\title{
A Brief Analysis of Educational and Technological Innovation in Universities
}

\author{
Yumian Liu and Shang Peng \\ Hunan Architecture Senior Technician School, Hunan Changsha, China \\ IBS School of Hunan University, Hunan Changsha, China \\ 239492576@qq.com,1397526193@qq.com
}

\begin{abstract}
Keywords: Educational innovation; Technological innovation; Innovative talents; Cultivation strategies; Research
\end{abstract}

\begin{abstract}
At the present stage, universities are the base for cultivating innovative talents and the cradle for innovative talents to grow; they play a very important role in the cultivation and growth of innovative talents. At this stage, the purpose of universities to adopt the new model of innovative lab is to make the talent cultivation mode of the universities transform towards the mode of technological innovation. This paper, chiefly through the research on the innovative lab mode of the universities, analyzes how the innovative lab organically combines educational innovation and technological innovation in the universities, discusses about the concrete development state, development features after the combination of innovative education and technological innovation at the present stage and the detailed problems existing in China's innovative education and technological innovation field, and puts forward corresponding coping strategies and plans for the problems, so as to offer references for the combination of educational innovation and technological innovation of the universities in China.
\end{abstract}

\section{Introduction}

Talent cultivation is the fundamental mission and intrinsic requirement of university education in China; it's also the primary criterion for measuring the university's teaching quality in China. Universities are the main cultivation base of innovative talents and play a crucial role in the growth of innovative talents. With the development of society, developed countries started to revolute the innovative mode years ago, pushing forward and doing research in the mode of innovative lab so as to fully combine educational innovation and technological innovation. At the present stage, internationally many countries have started to promote their own research in innovative labs with the purpose of integrating technological innovation into educational innovation. The innovative lab in China is still at the incubating stage; although we have made preliminary achievements in the cultivation of innovative talents and the construction of platform for technological innovation, yet there remain a lot of problems to be solved urgently. Innovative lab mode is different from the past enterprise incubator mode and university technology park mode; it focuses more on the combination of educational innovation and technological innovation and it's a brand-new leaping technology and mode. Innovative labs, with universities as the carrier, can effectively promote the transformation of technology results and have a significant practical meaning for the cultivation of innovative talents, and it can directly integrate technological innovation into educational innovation exquisitely.

\section{Specific Features and Development Status of the Integration of Educational Innovation and Technological Innovation in the Universities of China at This Stage}

Specific features and development status of the integration of educational innovation and technological innovation in the universities of China at this stage

In recent years, universities in China started to construct a lot of organizations and institutions with innovative lab as the name, with the purpose of integrating technological innovation 
exquisitely into the educational innovation of the universities. Many universities spontaneously set up their own innovative labs and some universities set up innovative labs cooperatively with research institutions or enterprises; some universities set up innovative labs cooperatively and in some cases government and universities set up innovative labs cooperatively. These innovative labs, in whatever forms established, chiefly aim to transform the innovative education mode and tightly combine the technological innovation and educational innovation of the universities. Through analysis, the concrete features of the present innovative labs are summarized in following aspects:

Firstly, externality. At this stage, innovative labs have generated the total factors of innovation and united the whole chain of innovation, and it's a brand-new innovative organizational management mode which effectively coordinates various innovation subjects. The innovative organizational management mode can effectively break the various barriers among the innovation bodies and facilitate the release of the capital, talents, technologies and information of each subject and the share of resources. This innovative lab can integrate innovation, production and application into one and form a complete industry chain; the links can be closely interconnected, facilitating the transformation of scientific research results and promoting the development of industry chain greatly. The coordinated development of the various links of universities, enterprises, and research institutions wins wide acceptance for the externality of innovative labs, mainly manifested as follows: firstly, enterprises' products, service and production have put forward new detailed requirements for basic theories and act as a strong impetus for the theoretical innovation of the research institutions and universities. With the development of society and the deepening of division of work, enterprises contract their R\&D departments to research institutions; the research institutions execute the research and development of new products and technologies, thus improving the progress of the research and development of new products and technologies of the research institutions and universities, facilitating the final transformation of innovation consciousness and thinking into technological achievements, and making the research institutions and universities cultivate more innovative talents of the new era who have innovation consciousness and thinking and close combination of educational innovation and technological innovation.

Secondly, openness. As innovative labs consist of various bodies which intermingle with each other, the communications among these bodies become ever more frequent than any other period. For instance, at this stage, the innovative media lab of Massachusetts Institute of Technology in U.S., as a completely open innovative lab, assembles over 180 enterprises, government agencies, academic research institutions and sponsors. There are very frequent interactions between the insiders of these organizations and the researchers of this innovative lab. Openness can promote the uplift of the researchers' innovation consciousness so that they have greater impetus for innovation. Therefore, innovative research is also very exclusive and global, making technological innovation integrate with educational innovation organically.

\section{The Specific Problems Existing in the Educational Innovation and Technological Innovation of the Universities in China at the Present Stage}

In recent years, the universities of China have made initial achievement in educational innovation and technological innovation; many universities have set up related courses of innovation education and also accumulated a lot of related experience. Most of the universities have incorporated the educational innovation and technological innovation of the students into high-efficiency university-operating system and provided strong support for multiple aspects like institution building, work guidance and training of teachers; meanwhile, they have formulated concrete measures and detailed regulations for educational innovation and technological innovation. However, there are still some weaknesses and problems needing to be solved in time:

First, there should be an extension in connotation for the cultivation of the talents of educational innovation and technological innovation of the universities in China. At the present stage, the innovative education of China's universities still take the teaching of knowledge and training of skills as the main body of teaching and education, but the improvement of students' innovative ability and the consciousness for cultivation of inter-disciplinary talents are less emphasized. 
Therefore, the universities of China should urgently break the traditional educational thinking and mode of education, proactively develop the deep-level connotation of innovative education and emphasize the cultivation of virtual and real personalities and abilities.

Second, the theory of the combination of educational innovation and technological innovation in China has not entered into the practice field of the disciplines of the universities. At the present stage, although the universities of China have set up the course on educational innovation and technological innovation, it's still the initiative of the universities. Therefore, the course is not systematic, lacking normalization and coerciveness; it hasn't been incorporated into the scope of specialized courses or become a main course in the universities. As the majority of the universities have opened only one course or two on technological innovation, no large scale can be formed and the desired teaching purpose cannot be reached. Compared with the innovative education courses in foreign universities, the number of our courses is not worth mentioning. Generally in foreign universities, there may be over 10 courses on technological innovation. So, during the development of the innovation teaching materials, the universities of China should take reference of the teaching material compiling experience of international advanced countries and make efforts to accomplish a quality teaching material on innovative education in line with China's actual national conditions, so as to provide assistance for the development and extension of technological innovation.

Third, the system of educational innovation and technological innovation of the universities in China should have further upgrade and transformations. The mode of purely professional education must be transformed to the mode of innovative talent education; the education boundary should be broken down and universities and enterprises should unite in order to promote the integration of educational innovation and technological innovation, and cultivate high-quality inter-disciplinary innovative talents. Thus, the functions of innovative labs will be authentically realized and the intrinsic features of the innovative labs will be highlighted and the technological innovation will be manifested in educational innovation of the universities.

\section{Study on the Cultivation Plan of the Technological Innovation Talents in Innovative Education of the Universities in China}

As the above problems in innovative education of the universities of China still exist and need to be solved urgently, the international advanced experience must be taken reference to and absorbed. In future development, the following aspects should be emphasized:

First, quality training should be strengthened so as to improve the consciousness of innovative education and technological innovation can be completely integrated with educational education. In the past teaching quality management mode of the universities, there was a lack of a teaching method which is heuristic, exploring and discussion-oriented and which can arouse the students to have queries and assumptions with situational models. Conventional stereotype teaching mode can only set the students on a unified thinking mode, which must be changed in view of university's teaching management. To cultivate the high quality professionals with innovative thinking, the students' innovative potentials have to be explored in view of the university's teaching management. There is no development without innovation. In case students' innovative ability has been improved, for the selection of teaching environment, there should be intriguing plots to extend the students' emotions and arouse the echo among the students so that the students can have a concrete feeling and correct understanding for the teaching contents and the students' thinking ability and research ability will be further improved. The stiff and stereotype situation of the university's teaching quality management mode will be improved. Classroom atmosphere is harmonious, classroom teaching mode is well reformed, and students' thinking becomes divergent, then the students' innovative ability will naturally be improved. University's exam-oriented education mode cannot stimulate students' innovative ability; therefore, it's an important direction for the cultivation of innovative talents in the universities of China to abandon the out-of-date education philosophies, emphasize the cultivation of innovative spirit, innovative quality and innovative consciousness, and strengthen quality education and innovative education. Only through the reform of the 
consciousness of educational innovation, can technological innovation and educational innovation be tightly integrated.

Second, the practical teaching link in the universities of China should be strengthened to promote the combination of educational innovation and technological innovation. Practical teaching is an important link in the cultivation of innovative talents and is good for improving the integrative competence of the university students; it's a great impetus for the improvement of innovative ability and practical ability. For university students, the development of integrative competence is especially important. It's not enough for students to have only professional knowledge, it's through the comprehensive development of integrative competence that they can make great sense of achievement in their future careers and get recognized by others. This requires university teaching management to strengthen the cultivation of students' outsight and innovative ability and emphasize the cultivation of students' knowledge so that the students can develop in an all-around way. Only if the students' integrative competence has been improved, can they have a better development in future study and life. Practical teaching can be completed in three concrete stages: curriculum design, practice, and graduation project. At this stage, to be the strong one in life, one must possess related integrative competence; it's far not enough to possess a certain specialized knowledge, students' communication ability, cooperation ability and organization ability must be exercised by way of concrete practical teaching link so that their integrative competence can develop in an all-round way. Only in this way, can the technological innovation and educational innovation combine fundamentally.

Third, the optimization of the knowledge structure of the university students in China should be strengthened and the humanistic education should be emphasized to improve the consciousness of technological innovation. Besides the professional knowledge, skills and the cultivation of the methods and practical ability for innovative, the technological innovative talents must possess comprehensive humanistic knowledge and quality. It's true that enterprises values the acquisition of basic knowledge and skills of this type of talents, yet for the students' future development, humanistic knowledge also plays a crucial role. Therefore, for university curriculum design, importance should be attached to the humanistic education of university students and related courses should be arranged to cultivate high quality comprehensive innovative talents who are adapted to the requirements of modern society and who possess both humanistic quality and professional innovative ability. Only in this way, can the consciousness of technological innovation be remarkably improved.

Fourth, some intensified training courses on educational innovation and technological innovation should be opened. The concrete intensified training courses will exercise the students' consciousness of innovation and develop their creativity. Personalized cultivation should be carried out, and teachers should make the best use of circumstances and teach the students according to their aptitudes.

\section{Conclusion}

In conclusion, modern society requires the university students to possess the knowledge, ability and integrative competence which can adapt themselves to the society. At this stage, the society in China is in a critical transformation period and enterprises have higher and new requirements for the practical ability and consciousness of technological innovation of the talents than ever before. The innovative labs of the universities of China need to absorb and borrow the advanced experience of the innovative labs of international developed countries, proactively construct a unique method of cultivation and education of innovative talents suitable for the development of the universities in China, provide technological innovative talents with high quality and comprehensive practical ability for enterprises of China. The interaction and cooperation between universities and enterprises should be actively developed in order to seek the joint development. 


\section{References}

[1] On the Technological Innovative Ability of Universities, Leng Feng, Shenyang Academic Annual Conference on Science, 2012.

[2] On the Technological Innovative Ability of Local Universities, Shi Zhenquan, Guo Chang, Chinese University Science \& Technology, 2014.

[3] The Platform for Cultivating Students' Practical and Creative Ability-Analysis on the impact of the university students' science and technology competition, Jiang Mingjian, Hu Zhaokui, Ma Guoyuan, Refrigeration and Air-conditioning: Beijing, 2013.

[4] Research and Practice of the Educational System of Innovation and Business Start-up in Local Engineering Universities, Wei Yinxia, Huang Ke, Guo Qing, Experimental Technology and Management, 2015.

[5] Approaches to Innovation and Entrepreneurship Cultivation, Zhang Xianyue, Xi Tingting, Heilongjiang Researches on Higher Education, 2015. 